\title{
Korespondensi Fonemis Bahasa Palembang dan Bahasa Riau
}

\author{
Riris Tiani \\ Fakultas Ilmu Budaya, Universitas Diponegoro \\ email: tiani.riris@gmail.com
}

\begin{abstract}
This study aims to describe the linguistic situation and the phonemic correspondence formula from Palembang and Riau language. The research method uses language grouping method with phonemic correspondence techniques. Palembang language and Riau language are languages derived from the same family, namely the Austronesian family. Language kinship is proven not only from the geographical location that is close together, but also evidenced in some gloss that has kinship in the field of phonemic correspondence. The phonemic correspondence formula can be seen between the Palembang language and the Riau language showing regular phonemic forms of correspondence in the form of vowels and consonants. The phonemic correspondence formulas in Palembang and the Riau languages obtained are: / $r \sim Q /, / a \sim o /, / \partial \sim a /, / j \sim t /$. Phonemic vocal and consensus correspondence occurs in open and closed peultima positions.
\end{abstract}

Key words: comparative historical linguistics, phonemic correspondence, Palembang Language, Riau language.

\begin{abstract}
Abstrak
Penelitian ini bertujuan untuk mendeskripsikan situasi kebahasaan dan formula korespondensi fonemis bahasa Palembang dan bahasa Riau. Metode penelitian menggunakan metode pengelompokan bahasa dengan teknik korespondensi fonemis. Bahasa Palembang dan bahasa Riau merupakan bahasa yang diturunkan dari satu rumpun yang sama, yakni rumpun Austronesia. Kekerabatan bahasa terbukti tidak hanya dari letak geografis yang berdekatan, tetapi juga dibuktikan pada beberapa gloss yang memiliki kekerabatan dalam bidang korespondensi fonemis. Formula korespondensi fonemis tersebut dapat dilihat antara bahasa Palembang dan bahasa Riau memperlihatkan bentuk korespondensi fonemis yang teratur dalam bentuk vokal maupun konsonan. Formula korespondensi fonemis dalam bahasa Palembang dan bahasa Riau yang didapat adalah: / $\mathrm{r} \sim Q /$, / a $\sim 0 /$ / / $\sim \mathrm{a} /, / \mathrm{j} \sim \mathrm{t} /$. Korespondensi fonemis vocal dan konsunan terjadi pada posisi penultima terbuka dan tertutup.
\end{abstract}

Kata kunci: linguistik historis komparatif, korespondensi fonemis, bahasa Palembang, bahasa Riau.

\section{Pendahuluan}

Pergerakan bahasa banyak dipengaruhi oleh perkembangan masyarakat penuturnya. Dalam alur pergerakan bahasa, perkembangan masyarakat penutur merupakan fakta empiris yang implikasinya belum lama disadari dalam perkembangan telaah bahasa. Berkembang atau tidak 
suatu bahasa sangat ditentukan oleh masyarakat penutur. Nababan (1991) menjelaskan bahwa awalnya perkembangan bahasa yang relatif berbeda terjadi pada tataran dialek saja yang menyebabkan komunikasi dua kelompok penutur bahasa tersebut masih dapat saling dimengerti. Makin berkembangnya masyarakat penutur dan gerak migrasi sosial, maka perbedaan dialek dalam masyarakat penutur semakin besar, hal ini dapat mengakibatkan terjadinya perbedaan bahasa, tetapi bahasa-bahasa tersebut masih berkerabat atau mempunyai satu bahasa tua atau proto.

Pada umumnya orang beranggapan bahwa suatu bahasa amat erat hubungannya dengan keadaan alam suatu bangsa dan keadaan budaya di daerah yang bersangkutan. Oleh karena itu, di dalam usaha menentukan batas-batas pemakaian suatu bahasa pun, didasarkan pada kenyataankenyataan tersebut. Begitu juga pada tingkat bahasa, perkembangan sesuatu bahasa atau dialek sangat tergantung kepada sejarah daerah yang bersangkutan. Perkembangan tersebut akan menyebabkan perubahan bahasa (Guiraud dalam Ayatrohaedi, 1979:5).

Perubahan bahasa adalah suatu fenomena yang bersifat semesta atau universal. Perubahan bahasa sebagai fenomena yang bersifat umum dapat diamati melalui perubahan bunyi. Dengan kata lain, perubahan itu secara mendasar dapat diamati pada tataran fonologi yang merupakan suatu tataran kebahasaan yang paling mendasar dan penting dalam rangka telaah di bidang linguistic bandingan (Fernandez dalam Masrukhi, 2002: 86). Perubahan bahasa tersebut dapat digunakan untuk mengamati kekerabatan antar bahasa. Dengan kata lain, dapat dilacak perubahannya dengan mengembalikan kepada bentuk protobahasanya, yaitu dengan cara mengamati perubahan pada tahap yang paling awal, yaitu perubahan bunyi pada tataran fonologis.

Dalam ilmu Linguistik Historis Komparatif, istilah korespondensi dipopulerkan oleh Jacob Grim, tokoh aliran Junggramatiker yang terkenal dengan Grims Law. Grims berpendapat bahwa bahwa bunyi-bunyi akan memiliki pergeseran secara teratur antara bahasa satu dengan bahasa lain tanpa kecuali (Crowley dalam Musayyedah, 2002: 355).Grims Law kemudian diganti dengan istilah korespondensi bunyi hakikatnya adalah suatu metode untuk menemukan hubungan antar bahasa dalam bidang bunyi bahasa. Teknik penetapan korespondensi bunyi antar bahasa lebih lanjut akan menjadi dasar untuk menyusun hipotesa mengenai bunyi proto dalam bahasa tua yang menurunkan bahasa-bahasa kerabat (Keraf, 1990: 40). 
Prinsip dasar yang harus dipegang dalam Linguistik Historis Komparatif adalah dua bahasa atau lebih dapat dikatakan kerabat apabila bahasa-bahasa tersebut berasal dari satu bahasa yang dipakai pada masa lampau. Selama pemakaiannya, semua bahasa mengalami perubahan dan bahasa bisa pecah menjadi dua atau lebih bahasa turunan. Adanya hubungan kekerabatan antara dua bahasa atau lebih ditentukan oleh adanya kesamaan bentuk dan makna.

Bentuk-bentuk kata yang sama antara berbagai bahasa dengan makna yang sama, diperkuat lagi dengan kesamaan-kesamaan unsur-unsur tata bahasa, dapat dijadikan dasar penentuan bahwa bahasa-bahasa tersebut berkerabat, yang diturunkan dari satu bahasa proto yang sama. Langkah kerja dalam Linguistik Historis Komparatif adalah: a) menekankan hubungan-hubungan antara bahasa-bahasa serumpun dengan mengadakan perbandingan mengenai unsur-unsur yang menunjukkan hubungan dan tingkat kekerabatan antar bahasabahasa itu, b) mengadakan rekonstruksi bahasa-bahasa yang ada dewasa ini kepada bahasabahasa yang dianggap lebih tua atau menemukan bahasa-bahasa proto yang menurunkan bahasa kontemporer, c) mengadakan pengelompokan (sub-grouping) bahasa-bahasa yang termasuk dalam suatu rumpun bahasa. Ada beberapa bahasa yang memperlihatkan keanggotannya lebih dekat satu sama lain apabila dibandingkan dengan beberapa anggota lainnya (Keraf,1990:23).

Indonesia merupakan negara yang memiliki keberagaman bahasa yang luar biasa. Sampai saat ini bahasa-bahasa Nusantara yang masih hidup dan berkembang dengan baik masih tersisa 786 bahasa. Berdasarkan hipotesis Grims Law bahwa bahasa di seluruh dunia dahulunya merupakan satu bahasa yang sama dari rumpun Austronesia. Maka, permasalahan dalam penelitian ini peneliti akan mencoba mengidentifikasi situasi kebahasaan bahasa Palembang (BP) dan bahasa Riau (BR) dan mendeskripsikan formula korespondensi fonemis bahasa Palembang dan bahasa Riau. Kedua bahasa tersebut sangat kental dengan dialek Melayu. Kedua bahasa tersebut masih dipergunakan masyarakat penutur dan berkembang di daerahnya. Daerah pentuturan yang saling berdekatan dan dalam satu pulau yang sama yakni pulau Sumatera. Secara geografis, kondisi masyarakat penutur yang berdekatan mendukung konsep kekerabatan bahasa.

\section{Metode}

Data direduksi dari kosakata dasar swadesh, yang telah teruji dalam beberapa bahasa yang retensi hilangnya selama 1000 tahun.Merujuk pada Tesasurus dan kamus bahasa daerah bahasa 
Palembang dan bahasa Jambi, gloss yang digunakan mewakili beberapa kategori kata, di antaranya kata ganti, bilangan, kata benda, dan kata kerja yang meliputi aktifitas sehari-hari. Aspek bahasa yang tepat dijadikan objek perbandingan adalah bentuk dan makna. Kesamaankesamaan bentuk dan makna itu akan lebih meyakinkan, karena bantuk-bentuk tersebut memperlihatkan kesamaan semantik. Kesamaan bentuk dan makna tersebut sebagai pantulan dari sejarah warisan yang sama. Bahasa-bahasa kerabat yang berasal dari bahasa proto yang sama selalu akan memperlihatkan kesamaan sistem bunyi (fonetik) dan susunan bunyi (fonologis).

Asumsi mengenai kata kerabat yang berasal dari sebuah bahasa proto yang didasarkan pada beberapa kenyataan berikut. Pertama, ada sebuah kosa kata dari kelompok bahasa tertentu secara relatif memperlihatkan kesamaan yang besar apabila dibandingkan dengan kelompok lainnya. Kedua, perubahan fonetis dalam sejajar bahasa-bahasa tertentu memperlihatkan pula sifat yang teratur. Keteraturan ini oleh Grimm dinamakan Hukum Bunyi.Ketiga, semakin dalam kita menelusuri sejarah bahasa-bahasa kerabat akan semakin banyak kesamaan antara pokok-pokok yang dibandingkan.

Setelah data diperoleh, akan dianalisis menggunakan metode perbandingan dengan teknik korespondensi fonemis. Korespondensi fonemis bertujuan untuk menemukan hubungan antarbahasa yang dibandingkan dalam bidang bunyi bahasa. Langkah kerja sebagai berikut, mengidentifikasi gloss yang diduga memiliki nilai korespondensi, membandingkan fonem demi fonem dari tiap segmen yang terdapat pada posisi yang sama, mengklasifikasikan dalam satu perangkat korespondensi, setelah didapat perangkat korespondensi yang muncul secara teratur dari bahasa yang dibandingkan, lalu merumuskan formula korespondensi dari bahasa yang dibandingkan.

\section{Pembahasan}

\section{Situasi Kebahasaan bahasa Palembang (BP) dan bahasa Riau (BR)}

Palembang adalah ibu kota provinsi Sumatera Selatan. Palembang merupakan kota terbesar kedua di Sumatera setelah Medan. Kota Palembang memiliki luas wilayah 358,55 km² yang dihuni 1,8 juta orang dengan kepadatan penduduk 4.800 per $\mathrm{km}^{2}$. Secara geografis, Palembang terletak pada $2^{\circ} 59^{\prime} 27.99^{\prime \prime} \mathrm{LS} 104^{\circ} 45^{\prime} 24.24^{\prime \prime} \mathrm{BT}$.

Masyarakat penutur bahasa Palembang sebagian besar berasal dari etnis Melayu yang menggunakan bahasa Melayu secara turun-temurun yang telah disesuaikan dengan dialek 
setempat. Dengan berkembangnya waktu, bahasa Melayu dialek Palembang saat ini dikenal sebagai bahasa Palembang. Sebagai kota yang padat penduduk, tentu mobilisasi penduduk terbuka lebar. Mobilisasi tersebut mempengaruhi eksistensi bahasa Palembang .Pengaruh mobilitas tampak pada keberagaman dialek bahasa Palembang. Dialek yang dominan digunakan oleh masyarakat penutur di sana di antaranya dialek Komering, Rawas, Musi, Pasemah, dan Semendo. Bahasa Palembang menjadi lingua franca sebagai bahasa pengantar sehari-hari. Selain penduduk asli, terdapat pula masyarakat pendatang dan keturunan, seperti

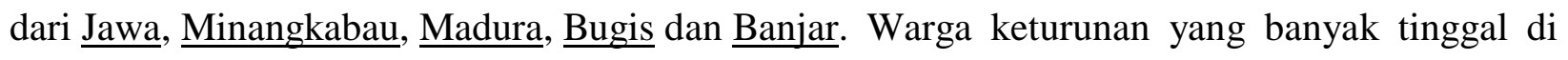
Palembang adalah Tionghoa, Arab, dan India. Kota Palembang memiliki beberapa wilayah yang menjadi ciri khas dari suatu komunitas seperti Kampung Kapitan yang merupakan wilayah Komunitas Tionghoa serta Kampung Al Munawwar, Kampung Assegaf, Kampung Al Habsyi, Kuto Batu, 19 Ilir Kampung Jamalullail dan Kampung Alawiyyin Sungai Bayas 10 Ilir yang merupakan wilayah Komunitas Arab.

Riau (Jawi: رياو) adalah sebuah provinsi di Indonesia yang terletak di bagian tengah pulau Sumatera dengan ibukota Pekanbaru. Secara geografis terletak di $0^{\circ} 42^{\prime}$ LU dan $101^{\circ} 55$ BT. Penduduk provinsi Riau terdiri dari bermacam-macam suku bangsa. $\underline{\text { Suku }}$ Melayu merupakan masyarakat terbesar dengan komposisi 37,74\% dari seluruh penduduk Riau. Mereka umumnya berasal dari daerah pesisir di Rokan Hilir, Dumai, Bengkalis, Kepulauan Meranti, hingga ke Pelalawan, Siak, Inderagiri Hulu dan Inderagiri Hilir. Suku bangsa lainnya yaitu Jawa (25, 05\%), Minangkabau (11,26\%), Batak (7,31\%), Banjar (3,78\%), Tionghoa $(3,72 \%)$, dan Bugis (2,27\%). Ada juga masyarakat asli Riau bersuku rumpun Minangkabau terutama yang berasal dari daerah Rokan Hulu, Kampar, Kuantan Singingi, dan sebagian Inderagiri Hulu.Juga masyarakat Mandailing di Rokan Hulu, yang lebih mengaku sebagai Melayu daripada sebagai Minangkabau ataupun Batak.

Bahasa pengantar masyarakat provinsi Riau pada umumnya menggunakan Bahasa

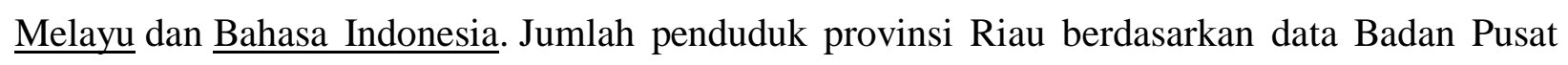
Statistik Provinsi Riau tahun 2010 sebesar 5.543.031 jiwa. Kabupaten/Kota yang memiliki jumlah penduduk terbanyak adalah Kota Pekanbaru dengan jumlah penduduk 903.902 jiwa, sedangkan Kabupaten/Kota dengan jumlah penduduk terkecil adalah Kabupaten Kepulauan Meranti yakni sebesar 176.371 jiwa. 


\section{Perangkat Korespondensi Fonemis bahasa Palembang dan bahasa Riau}

Berikut pasangan korespondensi fonemis ditemukan dalam segmen yang sama dan dalam pasangan kata yang memiliki kesaaan bentuk dan makna dalam beberapa gloss di bahasa Palembang dan bahasa Riau:

\begin{tabular}{|c|c|c|c|}
\hline Gloss & bahasa Palembang & bahasa Riau & $\begin{array}{c}\text { Korespondensi } \\
\text { Fonemis }\end{array}$ \\
\hline \multicolumn{4}{|c|}{$/ \mathrm{r} \sim Q /$} \\
\hline Akar & akar & aka & $/ \mathrm{r} \sim Q / \mathrm{C} \#$ \\
\hline Dengar & dəyar & dəya & $/ \mathrm{r} \sim Q / \mathrm{C} \#$ \\
\hline Kotor & kotor & kutu & $/ \mathrm{r} \sim Q / \mathrm{C} \#$ \\
\hline Lebar & lebar & leba & $/ \mathrm{r} \sim Q / \mathrm{C} \#$ \\
\hline Leher & leher & lehe & $/ \mathrm{r} \sim Q /-\mathrm{C} \#$ \\
\hline Lempar & lempar & lempa & $/ \mathrm{r} \sim Q /-\mathrm{C} \#$ \\
\hline Pikir & pikir & piki & $/ \mathrm{r} \sim Q /-\mathrm{C} \#$ \\
\hline Ular & ular & ula & $/ \mathrm{r} \sim Q / \mathrm{-C} \#$ \\
\hline
\end{tabular}

Perangkat Korespondensi fonemis $/ \mathrm{r} \quad \sim Q /$, fonem /r/ dalam bahasa Palembang berkorespondensi / / pada bahasa Riau terjadi pada beberapa pasang kata posisi akhir.

\begin{tabular}{|c|c|c|c|}
\hline Gloss & bahasa Palembang & bahasa Riau & $\begin{array}{c}\text { Korespondesi } \\
\text { Fonemis }\end{array}$ \\
\hline \multicolumn{3}{|c|}{$/ \mathrm{a} \sim \mathrm{o} /$} \\
\hline Kepala & kəpala & kəpalo & $/ \mathrm{a} \sim \mathrm{o} / \mathrm{- \#}$ \\
\hline Telinga & təlina & təlino & $/ \mathrm{a} \sim \mathrm{o} / \mathrm{- \#}$ \\
\hline Bunga & buya & buyo & $/ \mathrm{a} \sim \mathrm{o} / \mathrm{\#}$ \\
\hline Pada & pada & pado & / a $\sim \mathrm{o} /-\#$ \\
\hline
\end{tabular}

Perangkat Korespondensi fonemis /a o /, fonem /a/ dalam bahasa Palembang berkorespondensi fonemis dengan fonem /o/ dalam bahasa Riau pada posisi penultima terbuka.

\begin{tabular}{|c|c|c|c|}
\hline Gloss & bahasa Palembang & bahasa Riau & $\begin{array}{c}\text { Korespondensi } \\
\text { Fonemis }\end{array}$ \\
\hline
\end{tabular}




\begin{tabular}{|l|c|c|c|}
\hline \multicolumn{3}{|c|}{$/$ / $\sim \mathrm{a} /$} \\
\hline Dekat & dəket & dəkat & / $\sim \sim$ a / -C\# \\
\hline Tajam & tajəm & tajam & $/$ / $\sim$ / -C\# \\
\hline
\end{tabular}

Perangkat Korespondensi fonemis / a a/,fonem /o / dalam bahasa Palembang berkorespondensi fonemis dengan fonem / a / dalam bahasa Riau yang terjadi pada beberapa pasang kata dalam segmen yang sama. Korespondensi terjadi pada posisi penultima tertutup, apabila diikuti oleh konsonan bilabial $/ \mathrm{m} /$ dan konsonan palatal $/ \mathrm{t} /$.

\begin{tabular}{|c|c|c|c|}
\hline Gloss & bahasa Palembang & bahasa Riau & $\begin{array}{c}\text { Korespndensi } \\
\text { Fonemis }\end{array}$ \\
\hline \multicolumn{3}{|c|}{$/ \mathrm{j} \sim \mathrm{t} /$} \\
\hline Dorong & julak & Tolak & $/ \mathrm{j} \sim \mathrm{t} /-\mathrm{C \#}$ \\
\hline Lihat & jijok & Tejok & $/ \mathrm{j} \sim \mathrm{t} /-\mathrm{C \#}$ \\
\hline
\end{tabular}

Perangkat Korespondensi fonemis / $\mathrm{j} \sim \mathrm{t} /$, fonem / $\mathrm{j} /$ dalam bahasa Palembang berkorespondensi fonemis dengan fonem / $\mathrm{t}$ / dalam bahasa Riau yang terjadi pada segmen yang sama di beberapa pasang kata yang memiliki kemiripan bentuk dan makna. Korespondensi fonemis terjadi pada posisi penultima tertutup dengan diikuti konsonan dorsovelar /k/.

\section{Simpulan}

Berdasarkan analisis yang telah diuraikan, maka dapat ditarik simpulan bahwa bahasa Palembang dan bahasa Riau merupakan bahasa yang diturunkan dari satu rumpun yang sama, yakni rumpun Austronesia. Kekerabatan bahasa terbukti tidak hanya dari letak geografis yang berdekatan saja, tetapi juga dibuktikan pada beberapa gloss yang memiliki kekerabatan dalam bidang korespondensi fonemis. Formula korespondensi fonemis tersebut dapat dilihat antara bahasa Palembang dan bahasa Riau memperlihatkan bentuk korespondensi fonemis yang teratur dalam bentuk vokal maupun konsonan. Formula korespondensi fonemis dalam bahasa Palembang dan bahasa Riau yang didapat adalah: $/ \mathrm{r} \sim Q /, / \mathrm{a} \sim \mathrm{o} /, / \mathrm{a} \sim \mathrm{a} /, / \mathrm{j} \sim \mathrm{t} /$. Korespondensi fonemis vokal dan konsunan terjadi pada posisi penultima terbuka dan tertutup. 


\section{DAFTAR PUSTAKA}

Ayatrohaedi. 1979. Dialektologi: Sebuah Pengantar. Jakarta: Pusat Pembinan Bahasa, Departemen Pendidikan dan Kebudayaan.

Keraf, Gorys. 1990. Linguistik Bandingan Historis. Jakarta: Gramedia.

Masrukhi, Moh. 2002. "Refleksi Fonologis Protobahasa Austronesia (PAN) pada Bahasa Lubu (BL)". Jurnal Humaniora. Volume 14: Nomor I Februari 2002.

Musayyedah.2014. "Korespondensi Bunyi Bahasa Bugis Dialek Suppeng dan Dialek Ennak." Jurnal Sawerigading. Volume 20: Nomor 3 Desember 2014.

Nababan. P.W.J. 1991. Sosiolinguistik Suatu Pengantar. Jakarta: Gramedia Pustaka Utama. 